COMMENT

\title{
ECI biocommentary January 2020
}

\author{
Nadia Liotto (iD) \\ Pediatric Research (2020) 87:7; https://doi.org/10.1038/s41390-019-0651-x
}

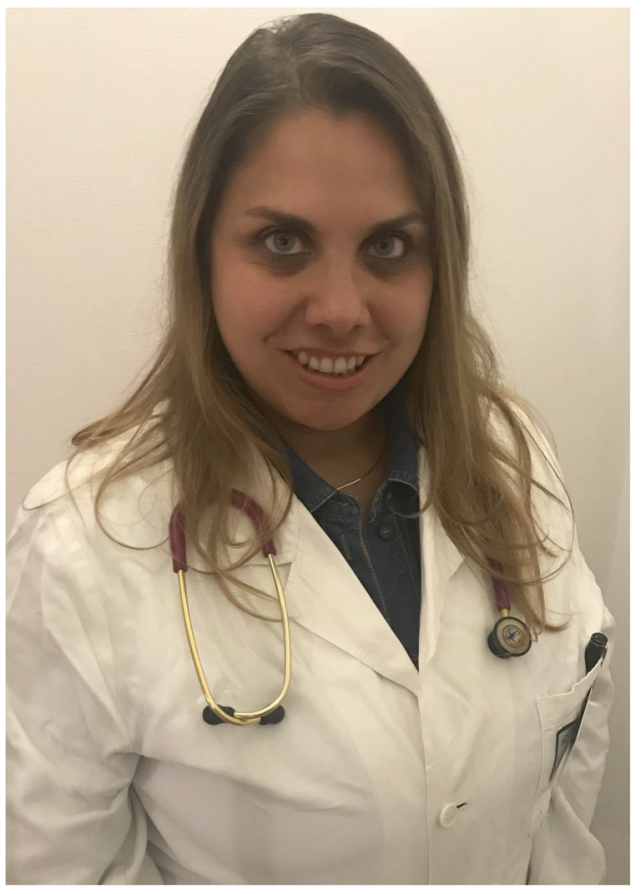

I was born and grew up near Milan, in Italy, and I am the oldest of three brothers.

From childhood, I dreamed of becoming a pediatrician. I studied at the Liceo Classico Carducci of Milan high school and later received my medical degree with top marks at the University Study of Milan, where my thesis was on X-linked agammaglobulinemia.

In 2008, I began PhD work in prenatal development sciences, diagnosis, and fetal therapy, and during my fellowship, I studied the nutritional outcomes of infants affected by intrauterine growth restriction.

As a resident in pediatric and neonatologic specialization at the School of Paediatrics of the University of Milan, I honed my interest in neonatal and infant nutrition. I obtained my specialization degree, achieving high grades with a thesis on the determinants of the body composition of premature infants at term-corrected age.

Since 2016, I have been a research physician in neonatal nutrition and neonatal intensive care and a member of the medical team at the Neonatal Nutrition Centre and the human milk bank of the Fondazione IRCCS Ca' Granda Ospedale Maggiore Policlinico, Neonatal Intensive Care Department, University Study of Milan.

In recent years, under the mentorship of Fabio Mosca and Paola Roggero, I have studied health monitoring, nutritional status, and neurodevelopmental outcomes of premature infants and newborns affected by gastrointestinal diseases or abdominal surgeryassociated diseases during or following a hospital stay.

In addition, I have developed an increasing interest in formulating research and implementation programs related to infants at high risk, particularly premature infants with very low birth weight $(<1500 \mathrm{~g})$ and late preterm infants.

My research activities center on growth and nutrition in neonates and infants-specifically, human milk, body composition, the microbiota, and neonatal resting energy expenditure.

In 2018, I became a member of the nutrition study group of the Italian Society of Neonatology and a member of the European Milk Bank Association.

In recent years, I have mentored students and residents in whom I always try to instill a desire to learn and the scientific curiosity that is crucial for the health of our little patients.

\section{ADDITIONAL INFORMATION}

Competing interests: The author declares no competing interests.

${ }^{1}$ NICU Fondazione IRCCS Ca' Granda Ospedale Maggiore Policlinico, Via della Commenda, 12 Milan 20122, Italy

Correspondence: Nadia Liotto (nadia.liotto@policlinico.mi.it)

Received: 30 September 2019 Accepted: 7 October 2019

Published online: 31 October 2019 